Nol ecul ar genetic epi demi ol ogy of homozygous fami I al hyperchol esterol emia in the Hokuri ku district of Japan

\begin{tabular}{|l|l|}
\hline 著者 & $\begin{array}{l}\text { Nabuchi Hi roshi, Nohar a At sushi, Noguchi } \\
\text { Tohr u, Kobayashi Junj i, Kawashi ri Masaaki, } \\
\text { Tada Hayat o, Nakani shi Chi aki, Mor i M ka, } \\
\text { Yanagi shi Nasakazu, I nazu Aki hi ro, Koi zumi } \\
\text { Junj i, Hokur i ku FH St udy Group }\end{array}$ \\
\hline $\begin{array}{l}\text { j our nal or } \\
\text { publ i cat i on ti t l e }\end{array}$ & At her oscl er osi s \\
\hline vol une & 214 \\
\hline number & 2 \\
\hline page r ange & 404 407 \\
\hline year & $2011-02-01$ \\
\hline URL & ht t p: //hdl . handl e. net /2297/26608 \\
\hline
\end{tabular}




\section{Molecular genetic epidemiology of homozygous familial hypercholesterolemia in the Hokuriku district of Japan}

Hiroshi Mabuchi ${ }^{\mathrm{a}, *}$, Atsushi Nohara ${ }^{\mathrm{a}}$, Tohru Noguchi ${ }^{\mathrm{a}}$, Junji Kobayashi ${ }^{\mathrm{a}}$, Masa-aki Kawashiri $^{\mathrm{b}}$, Hayato Tada ${ }^{\mathrm{b}}$, Chiaki Nakanishi ${ }^{\mathrm{b}}$, Mika Mori ${ }^{\mathrm{b}}$, Masakazu Yamagishi ${ }^{\mathrm{b}}$, Akihiro Inazuc, Junji Koizumi ${ }^{\mathrm{d}}$ and the Hokuriku FH Study Group

${ }^{a}$ Department of Lipidology, Graduate School of Medical Science, Kanazawa University, Japan ${ }^{\mathrm{b}}$ Division of Cardiovascular Medicine, Graduate School of Medical Science, Kanazawa University, Japan ${ }^{\mathrm{C}}$ Laboratory Science, Graduate School of Medical Science, Kanazawa University, Japan

${ }^{\mathrm{d}}$ General Medicine, Graduate School of Medical Science, Kanazawa University, Japan

*Corresponding author at: Department of Lipidology, Graduate School of Medical Science, Kanazawa University, Takara-machi 13-1, Kanazawa 920-8640, Japan

E-mail address: mabuchi@med.kanazawa-u.ac.jp

Keywords:

familial hypercholesterolemia (FH)

DNA analysis of FH genes

genetic epidemiology of homozygous $\mathrm{FH}$

incidence of $\mathrm{FH}$

A B S T R A C T 
Aim: Familial hypercholesterolemia (FH) is caused by mutations of $\mathrm{FH}$ genes i.e. LDL-receptor (LDLR), PCSK9 and apolipoprotein B (ApoB) gene. We evaluated the usefulness of DNA analysis for the diagnosis of homozygous FH (homo-FH), and studied the frequency of FH in the Hokuriku district of Japan.

Methods: Twenty-five homo-FH patients were recruited. LDLR mutations were identified using the Invader assay method. Mutations in PCSK9 were detected by PCR-SSCP followed by direct sequence analysis.

Results: We confirmed 15 true homozygotes and 10 compound heterozygotes for LDLR mutations. Three types of double heterozygotes for LDLR and PCSK9 were found. No FH patients due to ApoB mutations were found. The incidences of homo-FH and hetero-FH in the Hokuriku district were 1/171,167 and 1/208, respectively.

Conclusions: Our observations underlined the value of FH gene analysis in diagnosing homo-FH and confirmed extraordinarily high frequency of FH in the Hokuriku district of Japan.

\section{Introduction}

Familial hypercholesterolemia (FH) is an autosomal dominant disease characterized by the triad of (1) hypercholesterolemia due to a high level of plasma low-densitylipoprotein (LDL), (2) tendon xanthomas and (3) premature coronary heart disease [1]. Patients with homozygous FH (homo-FH) have two mutant alleles of either of three FH-associated genes (FH genes), which are as follows: LDL-receptor (LDLR), proprotein convertase subtilisin/kexin type 9 (PCSK9) and apolipoprotein B (ApoB) gene [2]. Homo-FH patients are likely to be identified in early childhood because of the early appearance of xanthomatosis associated with an exceptionally high plasma cholesterol levels (exceeding $15.6 \mathrm{mmol} / \mathrm{l}$ ), reflecting an extreme increase in LDL concentration. Use of the classical diagnosis of homo-FH and hetero-FH has led to an estimate of the prevalence of homo- and hetero-FH is 1 in 1,000,000 and 1 in 500 persons, respectively throughout the world [1]. The clinical phenotype of FH is highly variable and depends on the FH genes mutations present. Patients with a mild phenotype of homozygous FH often show a heterozygous phenotype of FH. Our aims of the present study were two. First we evaluated the molecular genetic epidemiology of homo-FH and then studied the frequency of hetero- and homo-FH in the Hokuriku 
district of Japan.

\section{Patients and methods}

\subsection{Diagnostic criteria of FH [3][4]}

\section{Hetero-FH}

a) Clinical diagnostic criteria are hypercholesterolemia with tendon xanthomas, or hypercholesterolemia in the first- or second-degree relative of $\mathrm{FH}$ patients.

b) Genetic diagnostic criteria are mutations of FH genes.

\section{Homo-FH}

a) Clinical diagnostic criteria are juvenile xanthomatosis with plasma cholesterol level about twice that of parents or other family members with hetero-FH

b) Genetic diagnostic criteria are true homozygotes, compound heterozygotes and double heterozygotes for FH genes.

\subsection{Patients}

Twenty-five clinically or genetically diagnosed homo-FH patients were selected for the study of genetic epidemiology of homo-FH and the calculation of the incidence of FH in the Hokuriku district. Written informed consent was obtained from each of the subjects prior to participation in the study.

\subsection{Laboratory measurements}

Blood samples for assays were drawn after overnight fasting. Concentrations of plasma total cholesterol (TC), triglyceride (TG) and high-density-lipoproteincholesterol (HDL-C) were determined at accredited clinical laboratories using routine clinical methods. LDL-cholesterol (LDL-C) concentrations were calculated using the Friedewald equation [5].

\subsection{FH genes analysis}

Detailed methods of FH genes analysis were described in our previous paper [6], 
and are described in brief here. Genomic DNA was prepared from white blood cells using a Genomic DNA Purification Kit (Gentra Systems, Minneapolis, MN, USA). Primers covering all of the exons and exon-intron boundary sequence of LDLR and PCSK9 were designed using Primer3 online software (http://frodo.wi.mit.edu/). LDLR mutations were identified using the Invader assay method (Third Wave Technologies, Inc., Madison, WI, USA) for point mutations previously identified in Japan [7]. The multiplex ligation-dependent probe amplification (MLPA) method for large rearrangements was performed using a P062B LDLR MLPA kit (MRC Holland, Amsterdam, Netherlands) and DNA sequencing was performed using a BigDye Terminator v3.1 Cycle Sequencing Kit (Applied Biosystems, Foster City, CA, USA) for the other mutations. ApoB mutations were screened by the methods reported in our previous paper [8]. Mutations in PCSK9 were detected by polymerase chain reaction (PCR) single-strand conformational polymorphism (SSCP) followed by direct sequence analysis.

\subsection{Statistical analysis}

Plasma lipid concentrations were compared among FH groups using Student's $t$-test. All data in the text are expressed as mean \pm SD. JMP 5.1.2 software (SAS Institute, Cary, NC, USA) was used for statistical analyses. $\mathrm{p}<0.05$ was considered statistically significant.

\section{Results}

\subsection{Genotypic analyses of homo-FH patients}

A DNA study of FH gene mutations was performed in all 25 clinically and genetically diagnosed homo-FH patients. Thirteen LDL-R mutants were found in these homo-FH patients, and one PCSK9 mutant (PCSK9 E32K) was found in five patients (Table 1). True homo-FH was confirmed in 15 patients (Table 1, Fig. 1), and six true homozygotes (13 patients) were for LDLR mutations, and one (2 patients) was true homozgyote for PCSK9 E32K. Four true homozygotes of Ex2-3del in three families and three homozygotes of D280Y in one family were born to consanguineous marriage. The geographical distributions of these homo-FH patients are shown in Fig. 1. Nine types of compound LDLR mutations were found in 10 homo-FH patients. Three types of LDLR 
and PCSK9 double heterozygotes were found. No case of FH patients due to ApoB mutation was found. No consanguineous marriage was found in these compound or double heterozygote families (Table 1, Fig. 1).

Thirteen cases diagnosed by DNA analysis showed less than $14.3 \mathrm{mmol} / \mathrm{L}$ of TC. Mean $( \pm \mathrm{SD})$ TC levels $(15.7 \pm 4.0 \mathrm{mmol} / \mathrm{L})$ in homo-FH patients confirmed by DNA analysis were significantly lower than those $(18.5 \pm 4.1 \mathrm{mmol} / \mathrm{L})$ diagnosed by clinical criteria $(\mathrm{p}<0.0442)$ [9]. Two patients who were true homozygotes due to a mutation in the PCSK9 gene were newly found among our homozygotes. PCSK9 E32K produced relatively mild homo-FH phenotypes. The mean $( \pm \mathrm{SD})$ plasma cholesterol level in homozygotes for LDLR gene mutations $(15.7 \pm 3.8 \mathrm{mmol} / \mathrm{L})$ was significantly higher than that $(11.3 \pm 3.2 \mathrm{mmol} / \mathrm{L})$ in true homozygotes or double heterozygotes for PCSK9 mutations $(\mathrm{p}<0.0276)$.

The outcomes of the patients are shown in Table 1. Seven patients died of cardiac death and one (M.K.) died of leukemia. Seventeen patients are alive, and 6 patients have been treated with LDL-apheresis, and 11 patients with medications (Table 1).

\subsection{Frequency of FH calculated using the Hardy-Weinberg equilibrium}

Among 11 true homo-FH families consanguineous marriage was detected in four. In the remaining seven families, there were no consanguineous marriages. In nine families of compound heterozygotes no consanguineous marriage was found (Table 1, Fig. 1). The Hardy-Weinberg equilibrium was used to calculate the frequency of hetero-FH. The frequencies of homo-FH, hetero-FH and unaffected persons are $\mathrm{p}^{2}, 2 \mathrm{pq}$ and $\mathrm{q}^{2}$, respectively (where $\mathrm{p}+\mathrm{q}=1$ ) and the general population in the Hokuriku district was $3,081,000$. If the 7 patients from consanguineous marriage were ignored, $\mathrm{p}^{2}$ could be $18 / 3,081,000=1 / 171,167$ and then $p=1 / 414$. As $q=1-p=413 / 414$, the frequency of the hetero-FH ( $2 \mathrm{pq})$ is $2 \times 1 / 414 \times 413 / 414=1 / 208$. Therefore, frequencies of the homo-FH and the hetero-FH were $1 / 171,167$ and $1 / 208$, respectively.

\section{Discussion}

It has been thought that homo-FH is easily diagnosed. However, it is sometimes difficult to differentiate severely affected heterozygotes from mild-type homozygotes without DNA analysis of FH genes. Recently, analysis of FH gene mutations has made it possible to identify presymptomatic homo-FH phenotype. DNA analysis of 
FH-associated genes shows true homozygote of identical heterozygous mutant, compound heterozygote of different heterozygous mutant of the same gene, and double heterozygote of different FH gene mutations. True homozygotes often came from a consanguineous marriage, whereas compound or double heterozygotes almost never did so. True homozygotes and compound heterozygotes for PCSK9 E32K show mild phenotypic homo-FH, compared with LDLR mutant homo-FH patients [6]. Currently, the diagnosis of FH involves clinical assessment and biochemical tests (lipid profile), but DNA-based testing will play a greater role in the identification and management of $\mathrm{FH}[10]$.

The prevalence of hetero-FH among the general population has been estimated to be at least, 1 in 500 among Caucasians, ranging from 1 in 200 to 1 in 1000 [11, 12]. In 1978, we summarized 51 homozygous patients with FH in Japan, and estimated the frequency of homo-FH in Japan as 1 in 1.45 millions, and that of hetero-FH as 1 in 500 [9]. However, the low incidence of FH in most countries is due to the low frequency of homo-FH diagnosed by classical diagnostic criteria based on physical signs, laboratory findings and data from the parents. In the present study genetic diagnosis detected unexpectedly mild phenotypic cases of homo-FH, and several new cases of homo-FH were discovered. As FH is an autosomal dominant genetic disease, the frequency of hetero-FH has been calculated by the incidence of homo-FH in the district using the Hardy-Weinberg equilibrium. Here we found an extraordinarily high incidence of FH in this district of Japan.

A remarkably high prevalence of $\mathrm{FH}$ has been reported in several areas of the world, owing to founder effects. In Lebanon, the estimated prevalence of homozygotes and heterozygotes is 1 in 10,000 and 1 in 171, respectively [13]. In the Hokuriku district of Japan, the most frequent mutation in hetero-FH was the K790X LDLR mutation, with a frequency of $31.7 \%$ [7]. However, this mutant was less frequent in the Osaka district (5.4\%) in Japan. No historical immigration records have been maintained in this district, and thus the K790X mutant of LDLR should not be classified as a founder gene in Japan, but only as a historically old mutant that prevailed locally and widely over a long period of time. High frequency of FH gene mutations might have produced true homozygotes without consanguineous marriage.

These observations underline the value of gene analysis in diagnosing hetero- and homo-FH patients and the extraordinarily high frequency of FH in this district of Japan.

\section{Conflict of interest}


There is no conflict of interest to disclosure.

\section{References}

[1] Goldstein JL, Hobbs HH and Brown MS. Familial hypercholesterolemia. in Scriver C, Beaudet A, Sly W, Valle D, Childs B, Kinzler K, Vogelstein B. Ed. The Metabolic and Molecular Bases of Inherited Disease, p2895, McGraw-Hill Professional $8^{\text {th }}$ ed, 2000.

[2] Soutar AK, Naoumova RP. Mechanisms of disease: genetic causes of familial hypercholesterolemia. Nat Clin Pract Cardiovasc Med. 2007;4(4):214-25.

[3] Mabuchi H, Higashikata T, Nohara A, et al. Cutoff point separating affected and unaffected familial hypercholesterolemic patients validated by LDL-receptor gene mutants. J Atheroscler Thromb. 2005;12(1):35-40.

[4] Scientific Steering Committee on behalf of the Simon Broome Register Group. Risk of fatal coronary heart disease in familial hypercholesterolaemia. BMJ. 1991; 303(6807):893-6.

[5] Friedewald WT, Levy RI, Fredrickson DS. Estimation of the concentration of low-density lipoprotein cholesterol in plasma, without use of the preparative ultracentrifuge. Clin Chem. 1972;18(6):499-502.

[6] Noguchi T, Katsuda S, Kawashiri MA, et al. The E32K variant of PCSK9 exacerbates the phenotype of familial hypercholesterolemia by increasing PCSK9 function and concentration in the circulation. Atherosclerosis. 2010;210(1):166-72.

[7] Yu W, Nohara A, Higashikata T, et al. Molecular genetic analysis of familial hypercholesterolemia: spectrum and regional difference of LDL receptor gene mutations in Japanese population. Atherosclerosis. 2002;165(2):335-42.

[8] Nohara A, Yagi K, Inazu A, et al. Absence of familial defective apolipoprotein B-100 in Japanese patients with familial hypercholesterolaemia. Lancet. 1995;345(8962):1438.

[9] Mabuchi H, Tatami R, Haba T, et al. Homozygous familial hypercholesterolemia in Japan. Am J Med. 1978;65(2):290-7.

[10] Kolansky DM, Cuchel M, Clark BJ, et al. Longitudinal evaluation and assessment of cardiovascular disease in patients with homozygous familial hypercholesterolemia. Am J Cardiol. 2008;102(11):1438-43.

[11] Goldstein JL, Schrott HG, Hazzard WR, et al. Hyperlipidemia in coronary heart disease. II. Genetic analysis of lipid levels in 176 families and delineation of a new inherited disorder, combined hyperlipidemia. J Clin Invest. 1973;52(7):1544-68. 
[12] Slack J. Inheritance of familial hypercholesterolemia. Atheroscler Rev 1979;5;35-66.

[13] Khachadurian AK. The inheritance of essential familial hypercholesterolemia. Am J Med 1964; 37:402-7.

\section{Figure Legend}

Fig.1. Geographical location of 25 homo-FH patients with FH gene mutations in the Hokuriku district of Japan 
Table 1

Clinical characteristics of 25 homo-FH patients in Hokuriku district of Japan.

\begin{tabular}{|c|c|c|c|c|c|c|c|c|c|c|c|c|c|c|}
\hline & $\begin{array}{l}\text { Case } \\
\text { No. }\end{array}$ & $\begin{array}{l}\text { Family } \\
\text { No. }\end{array}$ & Name & FH gene mutations & Sex & $\begin{array}{l}\text { Age } \\
\text { (yrs) }\end{array}$ & $\begin{array}{c}\mathrm{TC} \\
(\mathrm{mmol} / \mathrm{L})\end{array}$ & $\begin{array}{c}\mathrm{TG} \\
(\mathrm{mmol} / \mathrm{L})\end{array}$ & $\begin{array}{l}\text { LDL-C } \\
(\mathrm{mmol} / \mathrm{L})\end{array}$ & $\begin{array}{l}\text { HDL-C } \\
(\mathrm{mmol} / \mathrm{L})\end{array}$ & $\begin{array}{l}\text { ATT } \\
(\mathrm{mm})\end{array}$ & Father/Mother & $\begin{array}{l}\text { Consanguine- } \\
\text { ous marriage }\end{array}$ & Outcome \\
\hline \multirow{15}{*}{ 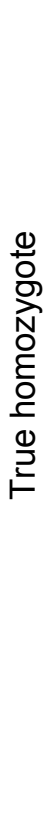 } & 1 & 1 & M.K. & Ex2-3del/Ex2-3del & $\mathrm{F}$ & 40 & 14.3 & 1.61 & 12.9 & 0.7 & 8 & ?/Hetero & + & $\mathrm{D}$ \\
\hline & 2 & 2 & H.Y. & Ex2-3del/Ex2-3del & $\mathrm{F}$ & 34 & 16.4 & 0.91 & 13.3 & 1.5 & 27 & ?/Hetero & + & $A(L D L-a)$ \\
\hline & 3 & 3 & T.T. & Ex2-3del/Ex2-3del & M & 49 & 14.5 & 4.38 & & & & ?/Hetero & + & $\mathrm{D}$ \\
\hline & 4 & 3 & Y.I. & Ex2-3del/Ex2-3del & $\mathrm{F}$ & 52 & 16.2 & 3.56 & 13.7 & 0.8 & 31 & ?/Hetero & + & $A($ med $)$ \\
\hline & 5 & 4 & M.I. & K790X/K790X & $\mathrm{F}$ & 20 & 19.0 & 3.08 & & & & Hetero/Hetero & $?$ & $\mathrm{D}$ \\
\hline & 6 & 5 & S.S. & K790X/K790X & $\mathrm{F}$ & 26 & 26.1 & 8.85 & & & 20 & Hetero/Hetero & - & $\mathrm{D}$ \\
\hline & 7 & 5 & Y.S. & K790X/K790X & $\mathrm{F}$ & 23 & 13.9 & 1.11 & 12.9 & 0.5 & 20 & Hetero/Hetero & - & $A(L D L-a)$ \\
\hline & 8 & 6 & S.Y. & D280Y/D280Y & M & 24 & 13.9 & 0.55 & 12.9 & 0.8 & 42 & Hetero/Hetero & + & $A(L D L-a)$ \\
\hline & 9 & 6 & K.Y. & D280Y/D280Y & $\mathrm{F}$ & 27 & 15.8 & 1.42 & & & 13 & Hetero/Hetero & + & $\mathrm{D}$ \\
\hline & 10 & 6 & K.M. & D280Y/D280Y & $\mathrm{F}$ & 40 & 15.9 & 2.03 & & & 25 & Hetero/Hetero & + & $D$ \\
\hline & 1 & 7 & M.N. & R395W/R395W & $\mathrm{F}$ & 73 & 15.6 & 1.21 & 14.4 & 0.6 & 11 & $? / ?$ & $?$ & $\mathrm{D}$ \\
\hline & 12 & 8 & A.Y. & V502M/V502M & M & 28 & 13.0 & 1.30 & & & 17 & Hetero/Hetero & - & $\mathrm{A}(\mathrm{med})$ \\
\hline & 13 & 9 & Y.E. & IVS15-3C>A/IVS15-3C>A & M & 1 & 23.6 & 3.39 & & & & Hetero/Hetero & - & $\mathrm{D}$ \\
\hline & 14 & 10 & S.Y. & PCSK9 E32K/PCSK9 E32K & $\mathrm{F}$ & 49 & 10.9 & 1.73 & 8.2 & 1.3 & 9 & $? / ?$ & $?$ & $A($ med $)$ \\
\hline & 15 & 1 & Y.G. & PCSK9 E32K/PCSK9 E32K & $\mathrm{F}$ & 44 & 8.4 & 1.95 & 6.1 & 1.4 & & Hetero/Hetero & - & $A($ med $)$ \\
\hline \multirow{10}{*}{ 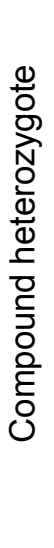 } & 16 & 13 & A.T. & K790X/P664L & M & 5 & 17.8 & 3.05 & 15.1 & 0.7 & 6 & Hetero/Hetero & - & A (LDL-a) \\
\hline & 17 & 13 & M.T. & K790X/P664L & M & 15 & 14.1 & 2.73 & 11.4 & 0.8 & 9 & Hetero/Hetero & - & $A(L D L-a)$ \\
\hline & 18 & 14 & N.Y. & $\mathrm{K} 790 \mathrm{X} / ?$ & $\mathrm{~F}$ & 36 & 11.1 & 1.05 & 9.5 & 1.0 & 14 & Hetero/Hetero & - & $A($ med $)$ \\
\hline & 19 & 15 & K.C. & $\mathrm{C} 163 \mathrm{R} / ?$ & $\mathrm{~F}$ & 21 & 12.8 & 0.80 & 11.1 & 1.4 & 10 & Hetero/Hetero & - & $A($ med $)$ \\
\hline & 20 & 16 & Y.T. & Exon3-6dup/? & M & 48 & 15.1 & 8.67 & & 0.8 & 30 & $? / ?$ & $?$ & $A($ med $)$ \\
\hline & 21 & 17 & M.M. & W23X/? & M & 36 & 12.0 & 2.42 & 9.8 & 1.0 & 28 & Hetero/Hetero & - & $A(L D L-a)$ \\
\hline & 22 & 18 & H.T. & R94H/W159X & M & 59 & 12.8 & 1.45 & 11.1 & 1.0 & 22 & $? / ?$ & - & $A($ med $)$ \\
\hline & 23 & 19 & Y.G. & IVS15-3C>A/PCSK9 E32K & M & 45 & 12.0 & 2.51 & 9.6 & 1.3 & 15 & ?/Hetero & - & $A($ med $)$ \\
\hline & 24 & 20 & T.K. & K790X/PCSK9 E32K & M & 1 & 9.0 & 2.55 & 6.4 & 1.4 & - & Hetero/Hetero & - & $A($ med $)$ \\
\hline & 25 & 21 & M.K. & C183S/PCSK9 E32K & M & 3 & 16.4 & 1.25 & 14.2 & 0.7 & - & Hetero/Hetero & - & $\mathrm{A}(\mathrm{med})$ \\
\hline \multicolumn{4}{|c|}{$\begin{array}{l}\text { Data are shown } \\
\text { D; deceased }\end{array}$} & $\begin{array}{l}\mathrm{F} \text { : female, } \mathrm{M} \text { : male } \\
\mathrm{A} \text {; alive }\end{array}$ & L-a; L & DL-aph & eresis & ckness & $\begin{array}{l}\text { Heter } \\
\text { med; }\end{array}$ & medicatic & & & & \\
\hline
\end{tabular}


Fig.1.

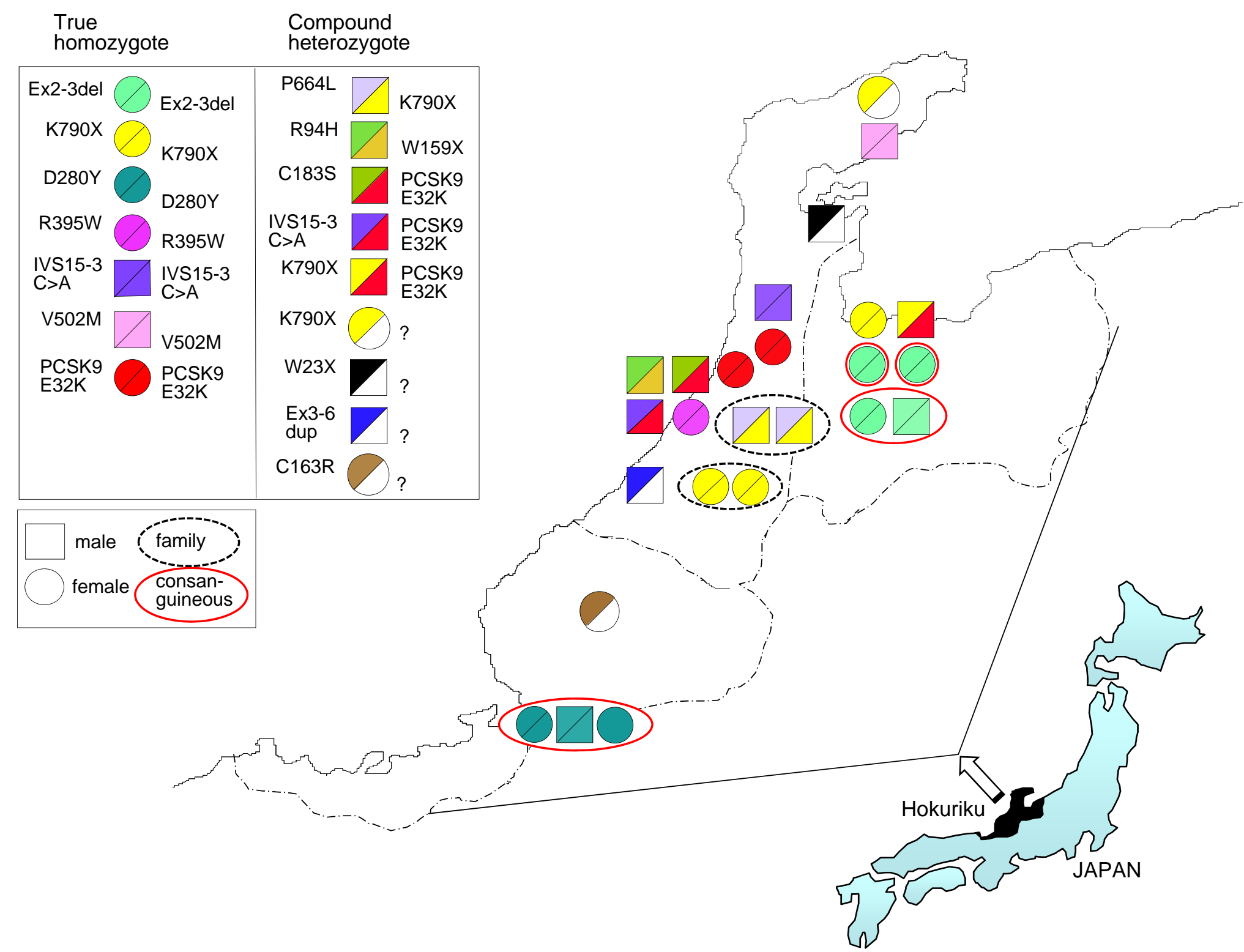

